\title{
Correction to: Fat intake during pregnancy and risk of preeclampsia: a prospective cohort study in Denmark
}

\author{
Mariel Arvizu - Myriam C. Afeiche - Susanne Hansen - Thorhallur F. Halldorsson - Sjurdur F. Olsen • \\ Jorge E. Chavarro
}

Published online: 28 June 2021

(c) The Author(s), under exclusive licence to Springer Nature Limited 2021

Correction to: European Journal of Clinical Nutrition https://doi.org/10.1038/s41430-018-0290-z

We were made aware that some of the panels in Fig. 2 were transposed and therefore did not match the panel label. Specifically, panels C and D were transposed with each other, and panels $\mathrm{E}$ and $\mathrm{F}$ were transposed with each other. The error in the order in which the panels were displayed does not affect referencing to the figure in the text, nor referencing to the panels in the figure legend. We apologize for this mistake. 
All cases of Preeclampsia $(n=1302)$

A
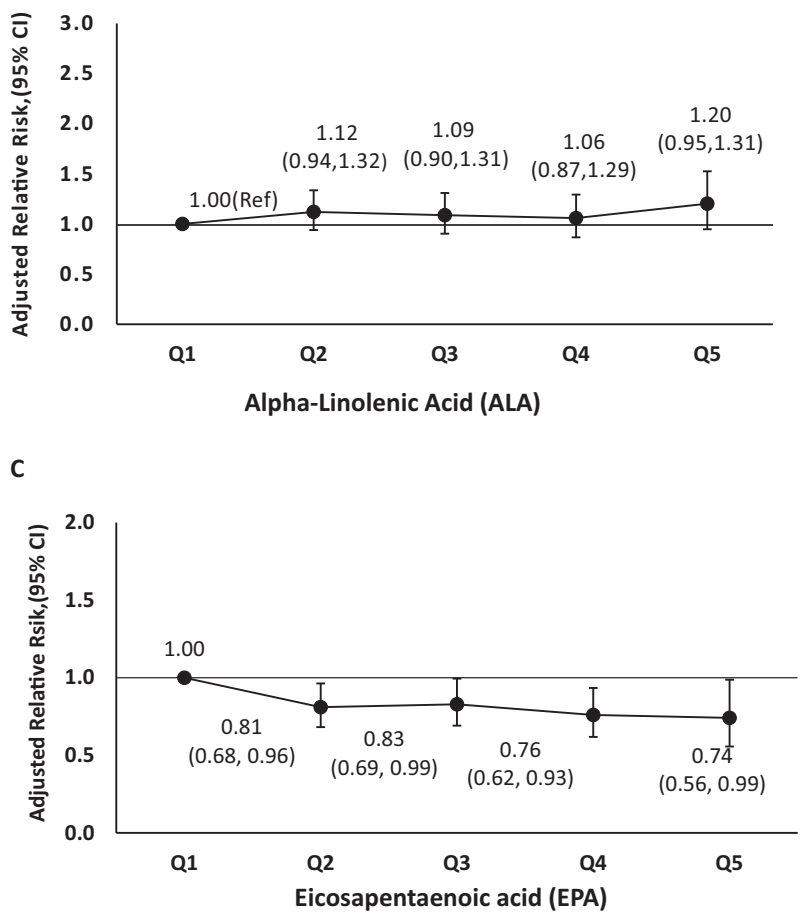

E

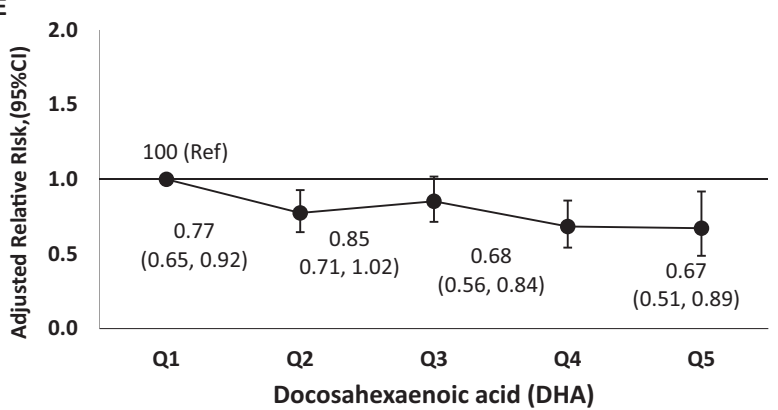

Severe Preeclampsia $(n=301)$

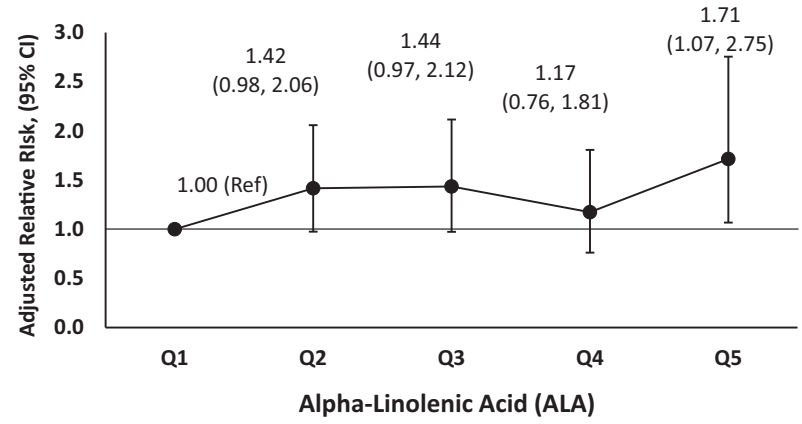

D

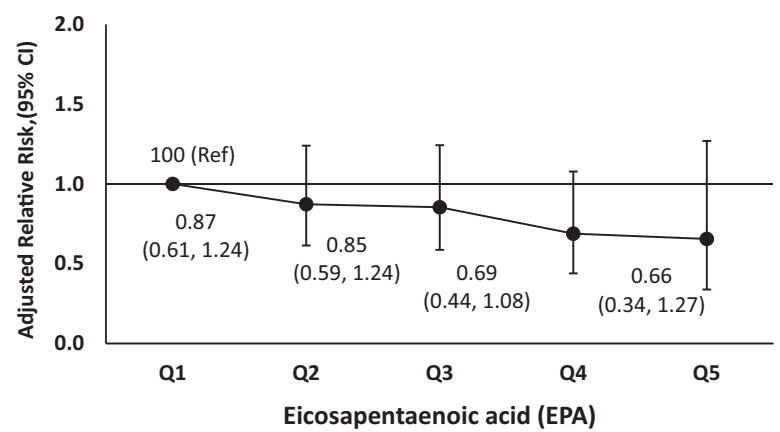

$\mathbf{F}$

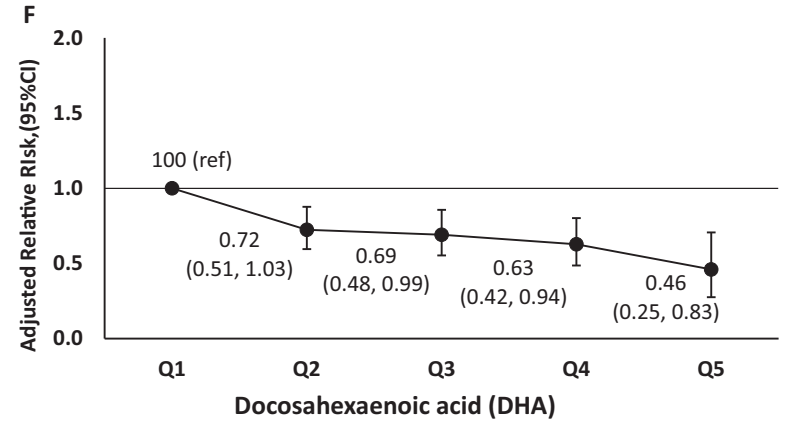

